Yuen, M., Lee, Q. A. Y. , Kam, J. \& Lau, P.S.Y. (2015). Purpose in life: A brief review of the literature and its implications for school guidance programmes. Journal of Psychologists and Counsellors in Schools. doi 10.1017/jgc.2015.18

\title{
Purpose in Life: A Brief Review of the Literature and its Implications for School Guidance Programmes
}

Mantak Yuen, Queenie A Y Lee, Jason Kam

The University of Hong Kong, China

Patrick S Y Lau

The Chinese University of Hong Kong, China

\section{Acknowledgements}

The preparation of this paper was partly funded by the Hong Kong Research Grant Council (HKU 756312H).

Contact Author: Mantak Yuen, Centre for Advancement in Inclusive and Special Education, Faculty of Education, The University of Hong Kong, Pokfulam, Hong Kong, China. Email: mtyuen@hku.hk

Queenie A Y Lee, Centre for Advancement in Inclusive and Special Education, Faculty of Education, The University of Hong Kong, Pokfulam, Hong Kong, China

Jason Kam, Centre for Advancement in Inclusive and Special Education, Faculty of Education, The University of Hong Kong, Pokfulam, Hong Kong, China

Patrick S Y Lau, Department of Educational Psychology, The Chinese University of Hong Kong, Shatin, Hong Kong, China

Submitted to Australian Journal of Guidance and Counselling January 182015

Re-submitted to Journal of Psychologists and Counsellors in School July 32015 


\title{
Purpose in Life: A Brief Review of the Literature and its Implications for School Guidance Programmes
}

\begin{abstract}
Purpose in life has emerged as an important notion in positive psychology. It is regarded as a factor that can contribute to any individual's wellbeing. Based on a review of the literature the authors discuss key issues that pertain to purpose in life, including how the construct is defined and conceptualized, its importance in living a fulfilling life, and the development of purpose across the lifespan. Because of its potential to contribute to positive youth development, the authors also discuss how extant research findings can inform school guidance and counseling interventions for adolescents. The P.A.T.H.S. Program in Hong Kong is used as an example to illustrate how students can be helped to establish their purpose in life through the guidance curriculum.
\end{abstract}

(121 words)

Keywords: adolescence; guidance and counselling; purpose in life 


\section{Introduction}

An important concept that has emerged in positive psychology is that of an individual's 'purpose in life'. Definitions of this concept vary, but they all tend to share three common components — commitment, goal-directedness, and personal meaningfulness (Bronk, 2014). Research to date seems to indicate that purpose in life must be considered a multidimensional construct that exerts an executive function on an individual's thoughts, beliefs and actions.

While issues related to purpose in life have been enriched by theory and by research with adults, much less is known about purpose in life among adolescents (Damon, Menon \& Bronk, 2003; Van Dyke \& Ellias, 2007). Insufficient attention has been given so far to investigating the evolution of an individual's purpose in life prior to adulthood, and the influences this may have on well-being (Burrow \& Hill, 2011; Damon et al., 2003). Recent trends have seen a move towards adopting a life-span perspective, with efforts made to identify developmental stages in discovering one's life purpose. Awareness of these stages could present the possibility of intervening in age-appropriate ways where necessary to promote positive youth development (Burrow, O'Dell, \& Hill, 2010). As a contribution towards this endeavor, this paper reviews some pertinent literature related to the concept of purpose in life, and then suggests possible forms of school intervention with a focus on adolescence.

\section{Literature Overview}

\section{Defining Purpose in Life}

McKnight and Kashdan (2009) posited that purpose is ' ... a central, self-organizing life aim that organizes and stimulates goals, manages behaviors, and provides a sense of meaning' (p. 242). These researchers suggested that, like a compass, purpose offers direction 
for individuals when making decisions and formulating life goals. They proposed five roles that purpose in life fulfills, namely: stimulating behavioral consistency, generating target motivated behaviors, stimulating psychological flexibility, fostering efficient personal resources allocation, and applying higher-level cognitive processing. Living a purposeful life necessitates the activation of all five roles to greater or lesser degrees; individuals vary, however, in the extent to which they implement action towards their purpose (Carver \& Scheier, 2002; McKnight \& Kashdan, 2009). The acquisition of purpose in life appears to be related to age, experience and cognitive ability (Damon, 2008; Moran, 2009).

\section{Conceptualizing Purpose in Life}

A recent review of definitions of 'purpose' in psychological and sociological research summarized three features related to purpose orientations, namely-foundation and direction, happiness, and prosocial intentions (Hill et al., 2010). First, the foundation and direction aspect of purpose can be noted in Ryff's (1989) observation that people with purpose in life recognize that they have set themselves goals and have a sense of direction. They feel there is meaning to their present and past life; and they hold beliefs that lead to aims and objectives for living. Moran (2010) suggested that the notion of 'purpose' is more abstract and longerterm than simply a 'goal' in life. It is the source of life-long self-regulation that can motivate an individual to invest great effort. Purpose can therefore be thought of as a higher-order attribute that provides context and foundation for the emerging of individuals' goals in life (Burrow \& Hill, 2011; Damon et al., 2003; Hill et al., 2010).

Regarding the 'happiness' aspect of having a purpose, Kosine, Steger and Duncan (2008) suggest that the attainment of personal goals moves people closer to achieving their true potential, thus bringing them intrinsic satisfaction and deeper fulfillment. This view is supported by a large body of empirical evidence suggesting that lack of purpose could be 
related to psychopathology, such as depression (Mascaro \& Rosen, 2005), and anti-social behaviors (Shek, Ma, \& Cheung, 1994). Citing research conducted over the past two decades, Bronk (2014) suggests that purpose could be related to a heightened stress level. Bronk reasoned that people who actively and strongly pursue life with a clear purpose could experience higher levels of stress because of their on-going desire to attain their goals. However, the sense of coherence provided by purpose may help these individuals cope with stress, as they can envisage accomplishing their goals. In spite of the findings that suggest having purpose in life may contribute to happiness and a sense of personal fulfillment, the direct link between purpose in life and positive affect has yet to be conclusively established.

The prosocial aspect of purpose is acknowledged by Damon et al. (2003) in their statement that purpose is '.. a stable and generalized intention to accomplish something that is at once meaningful to the self and of consequence to the world beyond the self' (p.121) [emphasis added]. This beyond-the-self aspect of purpose suggests that an individual with purpose has the desire to make a difference to the world and contribute to matters larger than self (Mariano \& Savage, 2009). Moran (2009) believes that a 'purposeful' individual has '...identified something to accomplish in the world that has consequences beyond themselves and their own self-interest, that has become an essential reason for their lives, and that has motivated them to be committed and engaged in relevant activities now and in the future' (p.147).

Other than the three above features delineated by Hill et al. (2010), McKnight and Kashdan (2009) saw purpose as having another three key aspects—scope, strength, and awareness-all interconnected by memories, emotions, and behaviors. Scope refers to how narrow or all-embracing a sense of purpose is in a person's life. Strength is represented in the power that purpose in life can exert on actions, thoughts, and emotions. Strong purpose can benefit an individual by bringing resilience that serves to overcome obstacles. Awareness 
reflects the extent to which a person knows (and can reflect upon) what their purpose in life is, and the extent to which it influences their actions. Awareness of purpose provides the individual with a sense of direction, and maintains mental and emotional well-being (McKnight \& Kashdan 2009).

All aspects identified above contribute to the construct of purpose in life. Together they represent multiple orientations related to personal growth (Hill, Burrow, Brandenberger, Lapsley, \& Quaranto, 2010). Each component may exert different degrees of influence on the life purposes in different individuals. Variations in the strength of the aspects may also reflect different cultural influences_-an issue explored more fully later.

\section{Multidimensionality of Purpose in Life}

Researchers have generally agreed that purpose is a multi-faceted construct. A study by Hill et al. (2010) explored the shorter- and longer-term relationships between different purpose orientations and personal well-being. Using factor analysis, they categorized purpose into four types-(1) pro-social orientation, (2) financial orientation, (3) creative orientation and (4) personal recognition orientation. This research suggested that among the various orientations, pro-social was the best predictor of well-being in adulthood.

Similarly, Moran (2009) suggested that purpose can be conceptualized along three dimensions, namely, (1) intention, (2) engagement, and (3) pro-social reasoning. Intention encompasses an orientation toward personal meaningfulness, accomplishment, and goals for the future. Intention is extremely important in life because an individual must be intrinsically motivated to carry out actions necessary for achieving personal goals successfully — rather than simply 'dreaming' of doing so. Engagement refers to the active process of committing one's personal resources (time, effort, social connections, reputation, knowledge and emotions) toward implementing intentions. Lastly, pro-social reasoning moderates intention 
and engagement by weighing in mind the consequences of one's intentions that may affect others. One important contribution of Moran's (2009) work is that clear purpose and intention in the pro-social domain could be regarded as a form of 'interpersonal intelligence' often accompanied by a sense of morality or 'moral giftedness' (Moran, 2010; Moran \& Gardner, 2006). For example, an individual who has developed a clear purpose in life is aware not only of how he or she can set personal goals and pursue a particular path, but can also anticipate how their decisions and actions could affect others. This form of intelligence helps the individual navigate the social environment and become more autonomous and purposeful (Moran, 2009; Moran \& Gardner, 2007).

\section{Controversy about the Importance of Purpose in Life}

Purpose in life as a psychological construct was first proposed by Viktor Frankl (1959). He observed that during World War II and the subsequent postwar years a significant number of individuals failed to find meaning in life, and exhibited symptoms of boredom, emptiness, and a lack of purpose. Frankl believed, however, that all human life has meaning and purpose under all circumstances, even in situations of intense or unavoidable suffering (Frankl, 1959). Because of this belief, he established a psychotherapy technique called logotherapy. The aim of the therapy was to utilize a most basic human motivation - to find a purpose for one's own existence-to help individuals recognize the significance of their own lives and the importance and usefulness of any actions they take (Crumbaugh, 1971; Crumbaugh \& Maholick, 1964; Maddi, 1967).

Some researchers are of the opinion that purpose is linked to physical and mental health. For example, having a purpose may lead to longer life span, fewer health-related problems and greater satisfaction in life (McKnight \& Kashdan, 2009). This view is supported by several studies that report an inverse relationship between having a definite purpose in life 
and maladaptive behaviors, such as participation in risky and antisocial action (Heisel \& Flett, 2004; Sappington \& Kelly, 1995; Sayles, 1994), drug involvement (Noblejas de la Flor, 1997), and alcoholism (Waisberg \& Porter, 1994).

Although empirical evidence suggests that having purpose in life is linked to greater life satisfaction and healthy living, researchers are divided on what actually constitutes purpose, and how the construct should be defined and measured. Unlike Frankl (1959), who assumed that pursuing a purpose that is personally meaningful is a basic human motivation, recent researchers have argued that purpose is not actually essential to well-being, and in fact may not be present in every person (McKnight \& Kashdan, 2009; Schnell, 2010). In support of this view, McKnight and Kashdan gave the example that an individual could be living a healthy life (mentally and physically) because of genetic and environmental factors, rather than from having a clear purpose or goal in life. These researchers also explored the nature of purpose by explicating its differences from religiosity and meaning in life. They suggest that:

'... purpose is not a mere product of faith, meaning, or personal agency. Meaning does not always drive purpose; rather, meaning probably drives the development of purpose. Once a purpose becomes developed, purpose drives meaning. In short, purpose and meaning have a temporal, bidirectional relationship' (McKnight \& Kashdan, 2009, p.243).

Research conducted so far seems to suggest that purpose in life could be oriented not only to betterment of the self but also to enhancing society through interactions with others. By utilizing Crumbaugh and Maholick's (1967) Purpose in Life Test (PIL), Damon et al. (2003) presented a number of studies that indicate a positive relationship between purpose in life and young people's commitment to social action (Butler, 1968; Martin, Nejad, Colmar, \& Liem, 2012). It is noteworthy that the pro-social aspect of purpose has been investigated in 
studies with adolescents in recent years, in order to examine its prevalence and relationship to optimal development (e.g., Mariano \& Vaillant 2012; Moran 2010).

\section{Differentiating Purpose in Life from Meaning in Life}

McKnight and Kashdan (2009) are not the only researchers who distinguish purpose in life from meaning in life. Although Frankl (1959) used the two terms interchangeably, those who followed him in this line of research drew some clear distinctions between the two constructs (Damon et al., 2003). For example Bronk (2014) defined the construct of purpose by contrasting it with meaning in life: 'Whereas purpose refers to a personally meaningful, far-horizon aim in life, most conceptions of meaning do not refer to goals or aims. Meaning in life, instead, encompasses both situational meaning and existential meaning...' (p. 7). On the other hand, Damon et al. (2003) proposed a hierarchical relationship between purpose and meaning, where meaning precedes purpose and where purpose is a subset of meaning alongside values, efficacy, and self-worth. It could be argued that a purpose in life is almost impossible to formulate in a life that lacks meaning.

In one of the earliest studies of the development of meaning in life, Battista and Almond (1973) suggested that an individual with a meaningful life makes positive commitments and perceives his or her own life as fulfilling. The literature indicates that there are many common sources of meaning for people. Schnell (2010), for example, summarized as many as twenty-six sources of meaning in four dimensions: (1) self-transcendence, (2) selfactualization, (3) order, and (4) well-being and relatedness.

Steger, Frazier, Oishi and Kaler (2006) defined meaning in life as '... the sense made of, and significance felt regarding, the nature of one's being and existence' (p. 81). The same idea was endorsed by King, Hicks, Krull and Del Gaiso (2006) who suggested that what one considers meaningful in life is subjective, hence '...lives may be experienced as meaningful 
when they are felt to have significance beyond the trivial or momentary, to have purpose, or to have a coherence that transcends chaos' (p. 180) [emphasis added]. When exploring the nature of meaning in life, Reker and Wong (1988) proposed that the construct has at least three components: cognitive (an understanding of one's experiences), motivational (a value system that drives one's actions) and affective (the feeling of satisfaction that is derived from achieving one's purpose).

Researchers have devised specific assessment tools to measure different facets of the "meaning in life" construct. Steger et al. (2006), for example, devised the Meaning in Life Questionnaire (MLQ), an instrument with two sub-scales measuring individuals' search for meaning in life (MLQ-S) and the presence of meaning (MLQ-P) separately. As pointed out by Steger et al. (2006), their research could help answer questions of how individual identity and purpose are formed — or fail to form — during adolescence. The validation of the MLQ marked an important improvement in tools available to assess meaning in life and thus may ultimately contribute to theory and research in the field.

\section{Development of Purpose in Life}

Searching for and establishing purpose in life refers to two related but distinct processes. These have been termed 'purpose exploration' and 'purpose commitment' (Burrow et al., 2010). Purpose exploration is essential for helping an individual reflect upon the broad range of alternative goals and pathways available in life, and then make personal choices and decisions. The next stage of purpose commitment is where the individual not only makes life choices but commits to them, at least in the short term. This delicate interplay between exploration and purpose commitment is extremely important during the adolescent years.

Burrow et al. (2010) suggest that the search for purpose in life is a complex process. Individuals often need time, experiences and guidance from others when considering options 
in life, and to avoid making commitments too soon. Researchers have been interested in exploring how purpose evolves in young people, and what constitutes purpose for them.

Regarding formation of purpose, Kashdan and McKnight (2009) suggested possible pathways for purpose to emerge in young people. These include: their own proactive efforts over time that result in a purpose; a transformative life event '.. where a purpose arises and adds clarity to the person's life; and social learning through observation, imitation, and modeling' (p.303). Similarly, Mariano (2014) stressed that contexts and opportunities proffered by the environment, or by people where youngsters are situated, determine the formation of purpose in adolescents.

It might be assumed that purpose develops in a linear fashion for all individuals typically shifting from a self-oriented to more others-oriented purpose — but Mariano suggests that it may develop in a more complex manner. Aspects of culture and society (for example, individualism versus collectivism) may play a role when individuals reflect upon and evaluate their emerging personal purpose. Values and purpose in life tend to vary across different ethnic groups; and Moran's (2014) work has attempted to explore how ethnicity may influence the way youths define purpose in life differently.

\section{Purpose in Life in Adolescents}

Puberty is an important time for establishing an identity and purpose in life; it is when most adolescents choose among the variety of 'ways-of-being' they see around them (Damon, 2008; Moran, 2010; Santrock, 2006). The search for and finding of a purpose in life is acknowledged as an important milestone in adolescence (Erikson, 1968). However it would appear that some researchers have neglected the issue of 'purpose development' in adolescents, because they assume that teenagers are not able to consider existential constructs (Fitzgerald, 2005). Counter to this belief, Hill et al. (2010) found that adolescents do define 
purpose in much the same way as adults reported in earlier research. The developmental aspect of acquiring purpose in life over time is reflected in the steady increase in the number of students who, when interviewed, can articulate their understanding of the concept of purpose (Damon, 2008; Moran, 2009; Moran, 2010). The study conducted by Hill et al. (2010) found that many adolescents hold quite mature and complex conceptions of purpose in life. The study revealed that almost all participants (98\%) were capable of describing what it means to 'have a purpose in life', and 68\% mentioned more than one theme. Pro-social elements were mentioned by $26 \%$ of adolescents, followed by the influence of religion (18\%) and occupational and financial themes (17\%). The adolescents were aware that purpose in life contributes to mental and emotional well-being.

Evidence (and common sense) suggests that developing a purpose in life is an asset for adolescents and can be a positive influence on their social and emotional growth. Those who develop a strong purpose early in the teen years are more likely to thrive (Benson, 2006; Burrow et al., 2010; Scales, 1999). As adolescents mature towards adulthood, most are capable of seriously reflecting upon their purpose in life and developing a sense of direction (Hill et al., 2010; Moran, 2009). High school graduates, for example, are expected to have formulated a purpose, and should know what they need to do to launch themselves as adults with a path to follow (Erikson, 1968; Moran, 2009).

Empirical studies on purpose in life among adolescents have found that their perception is positively associated with their ego strength and positive self-image. It was found that adolescents with a greater sense of purpose display increased life satisfaction, goal-directed thinking, and emotional well-being (Bronk, Hill, Lapsley, Talib, \& Finch, 2009; Burrow et al., 2010; Kiang \& Fuligni, 2010; King et al., 2006), and a lower tendency toward poor 
psychosocial adjustment (Shek, 1992), risk-taking behavior, and adolescent pregnancy (Walters \& Klein, 1980). During adolescence, awareness of purpose in life fosters a more flexible sense of personal planning and agency (Schwartz, Côte, \& Arnett, 2005), and is positively related to hope (Feldman \& Snyder, 2005) and a well-integrated personality (Mariano \& Vaillant, 2012).

In general, sense of purpose tends to increase with age across the period of adolescence to young adulthood, with beyond-the-self aspects of life being the last to develop in most individuals (Mariano \& Vaillant, 2012; Moran, 2009). This observation accords well with Piaget's perspective on cognitive development (Piaget, 1972), suggesting that the teen years are the stage at which most individuals develop the ability to think beyond self. This development allows adolescents to self-reflect, and also to show increased interest in other people and in the world (Magen, 1998). Similarly, it is believed that cognitive development during adolescence is associated with growth in moral reasoning abilities and self-discovery (Kohlberg, 1976). During adolescence, a sense of personal responsibility develops, resulting in the decline of hedonistic thinking and the rise of value-oriented moral reasoning (Eisenberg, 1991).

Adolescence is frequently described as a 'transitional stage' in life, involving autonomy seeking and identity exploration, (Burrow \& Hill, 2011; Erikson, 1968). The identity formation theory proposes that adolescents' active search for their own identity provides the context for them to explore what is personally valued and to pursue meaningful goals leading to commitment (Erikson, 1964). As the sense of purpose develops, it facilitates adolescents' resolution of identity crises (Erikson, 1968). In short, adolescence is a formative time for cultivating purpose in life as a key component in efficacious transition to adulthood (Burrow et al., 2010; Damon et al., 2003). 
Another perspective on the development of purpose during adolescence is evident in the identity capital model. This suggests that a stable 'sense of self' facilitates an individual's ability to navigate developmental transitions successfully. By knowing their own strengths, weaknesses and goals, individuals can cope with everyday experiences and can recognize potential obstacles and opportunities (Côte 1996; 1997; 2002). Purpose in life can therefore be considered a valuable form of capital which individuals may draw upon for personal growth (Côte 1997; Côte \& Schwartz 2002). Purpose in life anchors people's experiences to meaningful aspects of their identities, and generates beliefs that they can accomplish their personal goals (self-efficacy) (Côte \& Levine, 2002). Burrow and Hill (2011) infer that purpose may be interwoven with identity, thus influencing how individuals allocate their finite set of resources to maintain and promote well-being.

\section{Intervention: Implications for Guidance and Counselling Programmes}

In the context of education, particularly classroom teaching and school guidance activities, the work of Bundick and Tirri (2014) reinforced a view that teachers can make a positive difference to students' development of purpose. The research findings support the belief that personnel in schools (and others who come into regular contact with adolescents, such as sports coaches, trainers, youth club leaders, clergy) need to consider ways of fostering a student's sense of purpose. This is particularly relevant for students who do not seem to acquire a sense of purpose as a natural part of their maturation toward adult status. In some cases, specific intervention may be required for certain individuals.

Before implementing any intervention that aims at promoting the development of life purpose, it is important that an evaluation is made of students' current status or stage of development in this domain. Finding out 'where they are at' in terms of personal awareness and future orientations provides a baseline for which to monitor their progress over time. 
Bronk (2014) has remarked that traditional studies have tended to rely on inventories to measure purpose, but teachers and researchers should not ignore other forms of assessment to gather qualitative data, such as interviews, discussions, essays that require personal reflection, diaries, and other documents.

To facilitate the evaluation process tools have been developed to assess purpose and meaning in life. Most of the tools naturally reflect the different theoretical orientations of their designers (Reker \& Fry, 2003). One early example was developed by Frankl (1959), and it is now commonly referred to as the "Frankl Questionnaire". It contains 13 items that require self-report from respondents. In line with Frankl's work, Crumbaugh and Maholick (1964) developed the Purpose in Life Test (PIL) — still one of the most widely-adopted measures. The PIL has been criticized, however, because it does not assess an individual's commitment to causes beyond-the-self, and seems overall to assess only one factor (Bronk, 2014). Other assessment tools have also emerged, and although these assessment tools are now abundant, there are claims that adult measures may not be suitable for application with adolescents because the ideas explored may be beyond the maturity level and appreciation of teenagers (Damon et al., 2003). Similarly, many of the instruments are not sensitive to cultural or sub-group influences. It is suggested that a more suitable instrument would be the Life Purpose Questionnaire-Adolescent Version ( $L P Q-A)$ devised by Hutzell and Finck (1994). For example, researchers have found that this tool can significantly differentiate between a typical youth group and a youth support group for drug and alcohol problems.

Based on the literature reviewed above, in a school context intervention should focus on developing adolescents' self-understanding as a prerequisite for the nurturance of purpose. Self-understanding is a critical quality that enables individuals to reflect upon who they are and who they can become (Moran, 2009). This is the important process referred to by Burrow et al. (2010) as 'purpose exploration'. The development of self-understanding brings 
integration to aspects of self, purpose and action. This perspective sits comfortably with the contemporary aim in education to focus on supporting 'whole-person development' and helping adolescents become well-rounded, productive members of society (Damon, 2008; Quaglia \& Cobb, 1996).

In the secondary school setting, self-understanding can be promoted through programs that enable adolescents to reflect upon their own life experiences, review past and present relationships with family members and peers, and discuss future goals and purposes in life. The process of reflection allows them to discover meaning in their everyday actions, reactions and experiences (McKnight \& Kashdan, 2009). Discussion about different purposes in life provides an opportunity for adolescents to hear of their peers' purposes in life and thus gain deeper understanding. Guidance teachers can also help students explore purpose in life through examining the life of those who have gone through traumatic experiences, or those who engage in voluntary work, or engage in creative pursuits in a committed manner. Also, they should provide situations that help students gain greater self-awareness and ultimately influence their thinking and 'life plans' (Moran, 2009).

Most adolescents are mature enough to reflect upon issues related to purpose in life, so the guidance curriculum should also include activities that will enhance student's emerging sense of purpose. For example, the project Positive Adolescent Training through Holistic Social Programs (PATHS) used in Hong Kong schools is specifically intended to promote students' spirituality and sense of purpose (Shek \& Lau, 2006). The term 'spirituality' as used here concerns teenagers' ongoing need to understand their own inner nature, and to search for transcendence of self by seeking for meaning in life (Lau, 2006). Guiding students to explore the meanings of different incidents they have experienced in life can help them resolve personal doubts, confusions or lack of life direction. Comprehensive guidance programs in schools should have a component that enables students to explore such issues in 
an open and constructive manner. For some students, their religion will also be one of the elements that can influence self-reflection and purpose in life.

There does not need to be a formal 'curriculum' intended to force adolescents to adopt particular life plans and purposes. Instead, source material for discussion and reflection may come from topics related to traditional values and culture, social and political issues, personal relationships, religion, global concerns, humanistic endeavors, altruism, relationship with nature, financial security, family responsibilities, parenting, and meeting basic needs (Ardelt, 2003; Reker, 2000). Values related to humanistic concerns and altruism can be presented through news studies, role play and drama, and volunteer work. Encouragement for adolescents to learn from and reflect upon the above sources can provide insights for the development of purpose in life. The role of all schools is to enable this learning process to occur. As the field develops more fully in schools, it is hoped that teachers and guidance personnel will be able to use appropriate activities to evaluate student's stage of development in moving toward a purposeful life.

Intervening to foster purpose in life needs to take account of the cultural environment in which adolescents operate because, as indicated earlier, values and purposes in life tend to vary in different ethnic groups, and strategies that are appropriate in one setting may not be appropriate in another. For example, Moran (2009; 2010) suggests that the cultural norms in the US tend to focus on self-oriented life goals and individualistic pursuits, leading individuals first to consider personal happiness, satisfaction, and benefit to self above any pro-social and community needs (Diener \& Diener, 1996; Gable \& Haidt, 2005). In contrast, Chinese society values are often described as 'collectivistic', with an emphasis on commitment to the family and society before self. The Chinese have traditionally perceived pro-social purposes in life to be important for a person to 'live wisely'. Growing up as an adolescent in Chinese society one may thus be subjected to quite different influences and 
expectations, and thus purpose in life will be qualitatively different from that valued in the US (Meade \& Barnard, 1973; Shek, Hong \& Cheung, 1987; Yang 1970). Cultural differences must always be taken into account in any endeavors to develop or change the values, aspirations and life purposes of adolescents.

\section{Conclusion}

Adolescence is the formative time for development of purpose in life. A review of the literature suggests that purpose in life is a complex construct with various dimensions and is subject to a range of influences. Empirical findings from various studies, together with the theoretical notions of the purpose in life construct, provide educators with insights into the influences that may be at play on students' development and acquisition of purpose. The studies also reveal the importance for each individual of developing a clear purpose.

From both a review of the literature — and from their own current research—-the writers have found that five themes commonly emerge: (1) purpose is related to goal-setting and provides one with a foundation to achieve these goals; (2) purpose brings personal fulfillment or happiness; (3) purpose can be pro-social in nature, like making a difference to the lives of others in the same community; (4) purpose represents financial or occupational goals, such as becoming a successful and valued worker; and (5) purpose as being related to religion, or responding to one's vocation from God (Hill et al., 2010).

The nurturing of purpose for maturing adolescents must be recognized as one of the many humanistic responsibilities of all schools and colleges. Teachers and relevant others need to promote students' self-understanding, and provide opportunities for adolescents to explore and reflect upon their own goals and purposes in life. 


\section{References}

Ardelt, M. (2003). Effect of religion and purpose in life on elders' subjective well-being and attitudes toward death. Journal of Religious Gerontology, 14, 55-77.

Battista, J., \& Almond, R. (1973). The development of meaning in life. Psychiatry, 36, 409_ 427.

Benson, P. L. (2006). All kids are our kids: What communities must do to raise caring and responsible children and adolescents (2nd ed.). San Francisco, CA: Jossey-Bass.

Bronk, K.C. (2014). Purpose in life: A critical component of optimal youth development.

New York, NY: Springer Science + Business Media.

DOI: http://dx.doi.org/10.1007/978-94-007-7491-9

Bronk, K. C., Hill, P. L., Lapsley, D. K., Talib, N., \& Finch, H. (2009). Purpose, hope, and life satisfaction in three age groups. The Journal of Positive Psychology, 4, 500-510.

Bundick, M. J., \& Tirri, K. (2014). Student perceptions of teacher support and competencies for fostering youth purpose and positive youth development: Perspectives from two countries. Applied Developmental Science, 18(3), 148-162.

Burrow, A. L., \& Hill, P. L. (2011). Purpose as a form of identity capital for positive youth adjustment. Developmental Psychology, 47, 1196-1206.

Burrow, A. L., O’Dell, A. C., \& Hill, P. L. (2010). Profiles of a developmental asset: Youth purpose as a context for hope and well-being. Journal of Youth and Adolescence, 39, 1265-1273. 
Butler, A. C. (1968). Purpose in life through social action. Journal of Social Psychology, 74(2), 243-250.

Carver, C. S., \& Scheier, M. F. (2002). Control processes and self-organization as complementary principles underlying behavior. Personality and Social Psychology Review, 6, 304-315.

Côte, J. E. (1996). Sociological perspectives on identity formation: The culture-identity link and identity capital. Journal of Adolescence, 19, 417-428.

Côte, J. E. (1997). An empirical test of the identity capital model. Journal of Adolescence, 20, 577-597.

Côte, J. E. (2002). The role of identity capital in the transition to adulthood: The individualization thesis examined. Journal of Youth Studies, 5, 117-134.

Côte, J. E., \& Levine, C. G. (2002). Identity formation, agency, and culture: A social psychological synthesis. Mahwah, NJ: Erlbaum.

Côte, J. E., \& Schwartz, S. J. (2002). Comparing psychological and sociological approaches to identity: Identity status, identity capital, and the individualization process. Journal of Adolescence, 25, 571-586.

Crumbaugh, J. C. (1971). Frankl's logotherapy: A new orientation in counseling. Journal of Religion and Health, 10, 373-386.

Crumbaugh, J. D., \& Maholick, L. T. (1964). An experimental study in existentialism: The psychometric approach to Frankl's concept of noogenic neurosis. Journal of Clinical Psychology, 20, 200-207. 
Damon, W. (2008). The path to purpose: How young people find their calling in life. New York, NY: Free Press.

Damon, W., Menon, J., \& Bronk, K. C. (2003). The development of purpose during adolescence. Applied Developmental Science, 7, 119-128.

Diener, E., \& Diener, C. (1996). Most people are happy. Psychological Science, 7, 181-185.

Eisenberg, N. (1991). Values, sympathy, and individual differences: Toward a pluralism of factors influencing altruism and empathy. Psychological Inquiry, 2, 128-131.

Erikson, E. H. (1964). Insight and responsibility. New York, NY: Norton.

Erikson, E. H. (1968). Identity: Youth and crisis. New York, NY: Norton.

Feldman, D. B., \& Snyder, C. R. (2005). Hope and the meaningful life: Theoretical and empirical associations between goal-directed thinking and life meaning. Journal of Social and Clinical Psychology, 24, 401-424.

Fitzgerald, B. (2005). An existential view of adolescent development. Adolescence, 40, 793799.

Frankl, V. E. (1959). Man's search for meaning: An introduction to logotherapy. Boston, MA: Beacon.

Gable, S.L., \& Haidt, J. (2005). What (and why) is positive psychology? Review of General Psychology, 9, 103-110.

Heisel, M. J., \& Flett, G. L. (2004). Purpose in life, satisfaction with life, and suicide ideation in a clinical sample. Journal of Psychopathology and Behavioral Assessment, 26, $127-$ 135. 
Hill, P.L., Burrow, A.L., Brandenberger, J.W., Lapsley, D.K., \& Quaranto, J.C. (2010). Collegiate purpose orientations and well-being in adulthood. Journal of Applied Developmental Psychology, 31, 173-179.

Hill, P. L., Burrow, A. L., O’Dell, A. C., \& Thornton, M. A. (2010). Classifying adolescents' conceptions of purpose in life. The Journal of Positive Psychology, 5, 466-473.

Hutzell, R. R., \& Finck, W. C. (1994). Adapting the life purpose questionnaire for use in adolescent populations. The International Forum for Logotherapy, 17, 42-46.

Kiang, L., \& Fuligni, A. J. (2010). Meaning in life as a mediator of ethnic identity and adjustment among adolescents from Latin, Asian, and European American backgrounds. Journal of Youth and Adolescence, 39, 1253-1264.

King, L. A., Hicks, J. A., Krull, J., \& Del Gaiso, A. K. (2006). Positive affect and the experience of meaning in life. Journal of Personality and Social Psychology, 90, 179196.

Kohlberg, L. (1976). Moral stages and moralization: The cognitive developmental approach. In T. Lickona (Ed.), Moral stages and moral behavior (pp. 31-39). New York, NY: Holt, Rinehart and Winston.

Kosine, N.R., Steger, M.F., \& Duncan, S. (2008). Purpose-centered career development: A $\underline{\text { strengths-based approach to finding meaning and purpose in careers. Professional School }}$ Counseling, 12, 133-136.

Lau, P. S. Y. (2006). Spirituality as a positive youth development construct: Conceptual bases and implications for curriculum development. International Journal of Adolescent Medicine and Health, 18, 363-370. 
Maddi, S. R. (1967). The existential neurosis. Journal of Abnormal Psychology, 72, 311-325.

Magen, Z. (1998). Exploring adolescent happiness: Commitment, purpose, and fulfillment. Thousand Oaks, CA: Sage.

Mariano, J. M. (2014). Introduction to special section: Understanding paths to youth purpose-Why content and contexts matter. Applied Developmental Science, 18(3), 139-147. DOI: http://dx.doi.org/10.1080/10888691.2014.924356

Mariano, J.M., \& Savage, J. (2009). Exploring the language of youth purpose: References to positive states and coping styles by adolescents with different kinds of purpose. Journal of Research in Character Education, 7, 1-24.

Mariano, J. M. \& Vaillant, G. E. (2012). Youth purpose among the 'greatest generation'. The Journal of Positive Psychology, 7, 281-293.

Martin, A.J., Nejad, H., Colmar, S., \& Liem, G.A.D. (2012). Adaptability: Conceptual and empirical perspectives on responses to change, novelty and uncertainty. Australian Journal of Guidance and Counselling, 22 (1), 58-81. doi 10.1017/jgc.2012.8

Mascaro, N., \& Rosen, D. H. (2005). Existential meaning's role in the enhancement of hope and prevention of depressive symptoms. Journal of Personality, 73(4), 985-1013.

McKnight, P. E., \& Kashdan, T. B. (2009). Purpose in life as a system that creates and sustains health and well-being: An integrative, testable theory. Review of General Psychology, 13, 242-251.

Meade, R. D., \& Barnard, W. A. (1973). Conformity and anticonformity among Americans and Chinese. Journal of Social Psychology, 89, 15-24. 
Moran, S. (2009). Purpose: Giftedness in intrapersonal intelligence. High Ability Studies, 20, 143-159.

Moran, S. (2010). Changing the world: tolerance and creativity aspirations among American youth. High Ability Studies, 21, 117-132.

Moran, S. (2014). What "purpose" means to youth: Are there cultures of purpose? Applied Developmental Science, 18(3), 163-175.

Moran, S., \& Gardner, H. (2006). Extraordinary cognitive achievements: A developmental and systems analysis. In W. Damon (Series Ed.), \& D. Kuhn, \& R.S. Siegler (Vol. Eds.), Handbook of child psychology. Vol. 2: Cognition, perception, and language (pp. 905949). New York: Wiley.

Moran, S., \& Gardner, H. (2007). 'Hill, skill, and will': Executive function from a multiple intelligences perspective. In L. Metzler (Ed.), Executive function: From theory to practice (pp. 19-38). New York: Guilford Press.

Noblejas de la Flor, M. A. (1997). Meaning levels and drug abuse therapy: An empirical study. International Forum for Logotherapy, 20(1), 46-51.

Piaget, J. (1972). Intellectual evolution from adolescence to adulthood. Human Development, $15,1-12$.

Quaglia, R.J., \& Cobb, C.D. (1996). Toward of theory of student aspirations. Journal of Research in Rural Education, 12(3), 127-132.

Reker, G. T. (2000). Theoretical perspective, dimensions, and measurement of existential meaning. In G. T. Reker \& K. Chamberlain (Eds.), Exploring existential meaning. 
Optimizing human development across the life span (pp. 39-55). Thousand Oaks, CA: Sage.

Reker, G. T., \& Fry, P. S. (2003). Factor structure and invariance of personal meaning measures in cohorts of younger and older adults. Personality and Individual Differences, 35, 977-993.

Reker, G. T., \& Wong, P. T. (1988). Aging and the individual process: Toward a theory of personal meaning. In J. E. Birren \& V. L. Bengston (Eds.), Emergent theories of aging (pp. 214-246). New York: Springer.

Ryff, C. D. (1989). Happiness is everything, or is it? Explorations on the meaning of psychological well-being. Journal of Personality and Social Psychology, 57, 1069-1081.

Santrock, J.W. (2006). Life-span development (10 ${ }^{\text {th }}$ ed.). New York: McGraw Hill.

Sappington, A. A., \& Kelly, P. J. (1995). Self perceived anger problems in college students. International Forum for Logotherapy, 18, 74-82.

Sayles, M. L. (1994). Adolescents' purpose in life and engagement in risky behaviors: Differences by gender and ethnicity (Doctoral dissertation. University of North Carolinaat Greensboro, 1994). Dissertation Abstracts International, 55, 09A 2727.

Scales, P. C. (1999). Reducing risks and building developmental assets: Essential actions for promoting adolescent health. Journal of School Health, 69, 113-119.

Schnell, T. (2010). Existential indifference: Another quality of meaning in life. Journal of Humanistic Psychology, 50(3), 351-373. 
Schwartz, S. J., Côte, J. E., \& Arnett, J. (2005). Identity and agency in emerging adulthood:

Two developmental routes in the individualization process. Youth \& Society, 37, 201229.

Shek, D. T. L. (1992). Meaning in life and psychological well-being: An empirical study using the Chinese version of the Purpose-in-Life Questionnaire. Journal of Genetic Psychology, 153, 185-200.

Shek, D. T. L., Hong, E., \& Cheung, M. Y. P. (1987). The Purpose in Life questionnaire in the Chinese context. Journal of Psychology, 12, 77-83.

Shek, D. T. L., Ma, H. K., \& Cheung, P. C. (1994). Meaning in life and adolescent antisocial and prosocial behavior in a Chinese context. Psychologia, 37, 211-218.

Shek, D. T. L., \& Lau, P. S. Y. (2006). Development of a positive youth development program in Hong Kong: Project P.A.T.H.S. (Positive Adolescent Training through Holistic Social Programs). Journal of Basic Education, 15(1), 141-158.

Steger, M. F., Frazier, P., Oishi, S., \& Kaler, M. (2006). The meaning in life questionnaire: Assessing the presence of and search for meaning in life. Journal of Counseling Psychology, 53, 80-93.

Van Dyke, C.J., \& Elias, M.J. (2007). How forgiveness, purpose, and religiosity are related to the mental health and well-being of youth: A review of the literature. Mental Health, Religion, \& Culture, 10, 395-415.

Waisberg, J. L., \& Porter, J. E. (1994). Purpose in life and outcome treatment for alcohol dependence. British Journal of Clinical Psychology, 33, 49-63. 
Walters, L. H., \& Klein, A. E. (1980). A cross-validated investigation of the Crumbaugh Purpose-in-Life test. Educational and Psychological Measurement, 40, 1065-1071.

Yang, K. S. (1970). Authoritarianism and evaluation of appropriateness of role behavior. Journal of Clinical Psychology, 33, 65-68. 